\title{
Socio-Cultural Factors Affecting Pregnancy Outcomes in the Dangme West District of Ghana
}

\section{Adu J ${ }^{1 *}$, Owusu $\mathrm{MF}^{2}$ and $\mathrm{Adu} \mathrm{I}^{3}$}

${ }^{1}$ Faculty of Health Sciences, University of Western Ontario, Canada

${ }^{2}$ School of Health Sciences, Christ Church University, New Zealand

${ }^{3}$ St. Joseph's Hospital, Department of Adolescent Psychiatry, Canada

*Corresponding author: Joseph Adu, Faculty of Health Sciences, University Of Western Ontario,

\section{Research Article}

Volume 4 Issue 4

Received Date: July 06, 2020

Published Date: July 22, 2020

DOI: $10.23880 /$ nhij-16000224

Canada, Email: jadu@uwo.ca

\section{Abstract}

Background: Improvement in maternal healthcare services is crucial among nations as women are more vulnerable during pregnancy, especially in developing countries with poor health systems. This study assessed the socio-cultural factors that affect pregnancy outcomes in the Dangme West District of Ghana.

Methods: Qualitative methods were employed using the Dangme West District. Data was collected using key informant interviews involving health professionals in the area of maternal health care and focus group discussions with women attending antenatal clinic in the district.

Results: Findings from the study indicate that most women in the district attend antenatal clinics. They prefer delivering with Traditional Birth Attendants or in prayer camps to preserve their family tradition of not using health facilities during childbirth. Pregnancy outcomes are highly influenced by cultural traditions, with pregnant women avoiding nutritious foodstuffs such as eggs, certain types of fish, fatty meat, and some vegetables due to their beliefs, a situation resulting in pregnancy-related complications such as anaemia, premature delivery, and low birth weight. Key factors affecting maternal health outcomes include poverty, poor infrastructure in the district, nutrition, religious beliefs, illiteracy, and attitude of health professionals.

Conclusions: This study reveals a range of socio-cultural factors that impact directly on maternal health outcomes and which need to be targeted through appropriate public health actions.

Keywords: Socio-cultural factors; Pregnancy outcomes; Qualitative study; Dangme West District; Rural Ghana

Abbreviations: DDHS: District Director of Health Service; DPHN: District Public Health Nurse; PPHN: Principal Public Health Nurse; CHN: Community Health Nurse; LMI: Low and Middle-Income; SSA: Sub-Saharan Africa; TBAs: Traditional Birth Attendants; MOH: Ministry of Health; MAF: MDG 5 Acceleration Framework; CHPS: Community-Based Health Planning and Services; TPD: Three Phases of Delays; FGDs: Focus Group Discussions; ANC: Antenatal Clinics; IDIs: InDepth Interviews.

\section{Introduction}

Maternal health does not solely depend on women but also on the integrity of communities, societies, nations, and all individuals [1]. For centuries, countries in the low and middle-income (LMI) bracket have failed to protect women during pregnancy and childbirth because of a lack of functional health systems [2-4]. The strengthening of maternal and reproductive health services benefits to overall health systems. By enhancing access and use of a broad spectrum of reproductive health care services, LMI countries can save women from preventable deaths $[1,5,6]$.

Global statistics indicate that many high-income countries have made progress in increasing the availability of and access to maternal healthcare services to their people 
[7]. However, the majority of women in sub-Saharan Africa (SSA) remain without full access [7]. In 2015, the Maternal Mortality Ratio (MMR) for sub-Saharan Africa (SSA) was 546 deaths per 100,000 live births compared to only 12 deaths per 100,000 live births in the developed regions [5]. This alarming statistic in Africa has been attributed to a lack of access and availability of care by skilled attendants and the continued reliance on relatives or Traditional Birth Attendants (TBAs) in the region [8-10].

The African situation is not different from what prevails in Ghana, a country in SSA which has contributed significantly to the high MMR in the African region. Ghana's maternal mortality was declared a national emergency in 2008 [11]. Following the declaration, the Ministry of Health (MOH), the Ghana Health Service (GHS), and United Nations Development Programme (UNDP) developed the MDG 5 Acceleration Framework (MAF) to identify constraints to the implementation of existing policies to understand why pregnant women continue to die in Ghana [11]. This notwithstanding, very little progress has been achieved thus far in improving maternal health care in Ghana.

Existing literature in Ghana identifies socio-cultural factors such as illiteracy, values, beliefs, and attitudes as relevant elements to be considered in addressing the problem of maternal mortality in Ghana [12-14]. Although sociocultural factors have been identified as crucial in addressing maternal mortality in Ghana, studies have predominantly been conducted in the Northern part of Ghana where poverty is highest, and deeply rooted cultural inclinations permeate every facet of life. Thus, there is a paucity of such studies in the Southern parts of the Ghana. There is a big difference in socio-cultural disposition between Northern and Southern Ghana. As such, there is need for a study to understand the socio-cultural factors that affect maternal health care, specifically in the Southern Ghana. In this article, we use a case study of the Dangme West District in the Southern part of Ghana to give an empirical insight into socio-cultural factors affecting maternal health outcomes in Southern Ghana.

\section{Methods}

\section{Study Area}

The Dangme West District is purely rural and had a total population of 103,584 covering a land mass of $1,522.00 \mathrm{~km} 2$ in 2010. The district was divided into four administrative sub-districts: Dodowa, Prampram, Great Ningo, and Osudoku. The district had only one hospital at the time of this study, the Dodowa Government Hospital, which serves as the district hospital for general and referral purposes. The Dodowa hospital is supported by health centers, Communitybased Health Planning and Services (CHPS) compounds and zones, and private clinics and maternity homes. One of the three Health Research Centers of the GHS tasked with the responsibility of conducting research within the health sector is situated in the Dangme West District. The Dodowa Health Research Centre has a close working relationship with the Dangme West District health administration. This research was a hospital-based study which collected data from the Dodowa hospital and three other community clinics located at Agomeda, Ayikuma, and Osuwem.

This study adopted the Health Belief Model (HBM) [15-19] and the Three Phases of Delays (TPD) model by Thaddeus and Maine [20] to better expound our results. The HBM posits that individuals' health-related behaviour is contingent on their perception of the severity of their illness, their susceptibility to the disease, their understanding of the benefits of seeking care, and the barriers associated with the decision to seek care [15]. The individual's perceived severity of their ailment determines their likelihood of accessing care to reduce the intensity of the problem. This, however, depends on the individual's knowledge of the risks associated with their ailment, as well as the perceived benefits of seeking healthcare. Obstacles such as religious and cultural beliefs, danger, lack of access to health care, and poor road networks act as barriers to the intended positive actions of the individual to seek health care [20]. Thus, the HBM model envisages that the preparedness of people to embark on health-seeking behaviour to promote their health rests on the seriousness of the health-related problem, perceived threat, and access to affordable health care in communities [18]. In the case of this study, the individual in question is the pregnant woman who needs to seek health care from pregnancy through childbirth to post-natal care.

The TPD model by Thaddeus and Maine [20] suggests that three forms of delays confront pregnant women and their families while seeking care. These include delays in deciding to seek care on the part of the individual, the family, or both, delay in reaching an adequate health care facility, and delay in receiving adequate care in the facility. The readiness of the pregnant woman to use maternal health services depend on a host of factors including cost of care, distance, attitude, availability and cost of transport, quality of care and previous experiences of the woman [20]. The joint effects of the client's belief system and other access-related factors regarding the uptake of maternal health services; as postulated by the two models could help to better understand and explain the influence of sociocultural factors on pregnancy outcomes in the Dangme West District [21].

\section{Data Collection and Analysis}

This is a qualitative study using interviews and focus groups to explore the views of key informants in maternal 
healthcare delivery in the Dangme West District. A case study design allowed the researchers to study the entire district as a unit for extensive exploration [22].

\section{Key Informant Interviews}

Interview participants consisted of eleven maternal health professionals: one doctor and ten nurses (midwives and community health nurses) within the Dangme West District. The eleven participants were selected for interviews using purposive sampling [23]. Participants were selected for interviews based on their experience and knowledge of maternal healthcare delivery in the district. Participants were selected after contact by the district health administration and following an explanation of the purpose of the study socio-cultural factors affecting maternal health outcomes in the district. Recruitment occurred after contact with the management of respective health institutions who assisted in the identification of suitable participants. Participants signed consent forms to be included in the study. Participants were required to have worked in the district for at least three years.

Interview participants were selected from the Dodowa Hospital, Agomeda CHPS Zone, Ayikuma CHPS compound, and Osuwem CHPS compounds. These are health facilities within the district where pregnant women and women within the first six months post-delivery attend antenatal and post-natal clinics. The CHPS is an innovative approach to primary care adopted by the GHS and the Ministry of Health where health personnel such as a midwife and a few nurses move to settle permanently in hard-to-reach communities. Since maternal health services are provided through the CHPS zones and compounds outside the catchment of the district hospital, these were selected strategically to give representation to the entire district. In Ghana, health services are managed by a director in each district. Senior nurses support the implementation of public health initiatives in districts, particularly maternal health services [12]. Consequently, to gain deeper insights into maternal health factors in the district, the District Director of Health Services, a Principal Public Health Nurse and a District Public Health Nurse were selected for in-depth interview. In addition, since midwives are involved in the day-to-day delivery of maternal services in Ghana, 8 midwives were selected based on their location of practice and experience in the district. In all, 8 senior midwives were selected from the Dodowa Hospital (3), Ayikuma CHPS compound (2), Agomeda CHPS zone (2) and Osuwem CHPS compound (1). Table 1 provides details of the interview participants.

\begin{tabular}{|c|c|c|c|}
\hline Position & Age & Sex & Years of Experience \\
\hline DDHS & 44 & F & 11 \\
\hline DPHN & 58 & F & 30 \\
\hline PPHN & 40 & F & 3 \\
\hline Midwife & 29 & F & 15 \\
\hline Midwife & 51 & F & 10 \\
\hline Midwife & 40 & F & 3 \\
\hline CHN & 24 & F & 3 \\
\hline CHN & 26 & F & 10 \\
\hline Midwife & 42 & F & 3 \\
\hline CHN & 27 & F & 3 \\
\hline CHN & 25 & F & \\
\hline
\end{tabular}

Table 1: Key informant interview participants.

\section{Focus Group Discussions (FGDs)}

Two focus group discussions consisting of nine participants each were conducted with pregnant women. The FGD respondents were mostly women with b school education as well as others without any formal education. The groups were made up of farmers, hairdressers, petty traders, and housewives. The mean age of the women was 31.11 years. See Table 2 below for details. Contact was made with midwives in charge of antenatal clinics (ANC) in the health facilities who assisted in the introduction of the study to women attending ANC. Participants were then voluntarily invited and recruited using a recruitment script designed by the researchers. The inclusion criterion for the focus groups was women who attended ANC at the selected health facilities Dodowa hospital and Agomeda CHPS zone for the study. 


\begin{tabular}{|c|c|c|c|c|c|}
\hline FGD No. & Participants No. & Sex & Age [Years] & Occupation & Education \\
\hline \multirow[t]{9}{*}{1} & 1 & $\mathrm{~F}$ & 42 & Farmer & JHS \\
\hline & 2 & $\mathrm{~F}$ & 31 & Housewife & NA \\
\hline & 3 & $\mathrm{~F}$ & 28 & Trader & JHS \\
\hline & 4 & $\mathrm{~F}$ & 30 & Hairdresser & JHS \\
\hline & 5 & $\mathrm{~F}$ & 32 & Housewife & N/A \\
\hline & 6 & $\mathrm{~F}$ & 39 & Housewife & $\mathrm{N} / \mathrm{A}$ \\
\hline & 7 & $\mathrm{~F}$ & 20 & Trader & JHS \\
\hline & 8 & $\mathrm{~F}$ & 25 & Hairdresser & JHS \\
\hline & 9 & $\mathrm{~F}$ & 40 & Farmer & JHS \\
\hline \multirow[t]{9}{*}{2} & 1 & $\mathrm{~F}$ & 35 & Trader & JHS \\
\hline & 2 & $\mathrm{~F}$ & 37 & Housewife & $\mathrm{N} / \mathrm{A}$ \\
\hline & 3 & $\mathrm{~F}$ & 22 & Trader & $\mathrm{N} / \mathrm{A}$ \\
\hline & 4 & $\mathrm{~F}$ & 26 & Trader & $\mathrm{JHS}$ \\
\hline & 5 & $\mathrm{~F}$ & 28 & Farmer & JHS \\
\hline & 6 & $\mathrm{~F}$ & 41 & Hairdresser & $\mathrm{N} / \mathrm{A}$ \\
\hline & 7 & $\mathrm{~F}$ & 23 & Housewife & JHS \\
\hline & 8 & $\mathrm{~F}$ & 32 & Housewife & $\mathrm{N} / \mathrm{A}$ \\
\hline & 9 & $\mathrm{~F}$ & 29 & Housewife & JHS \\
\hline Total & 18 & & Mean Age = 31.11 & & \\
\hline
\end{tabular}

Table 2: Profile of focus group respondents.

\section{Data Collection}

The process of data collection started with the preparation of an interview guide based on the objectives of the study and the literature. The guide consisted of a loose frame of open-ended questions meant to guide interviewees towards the information sought. After the Institutional Review Board granted permission for the study, the investigators approached the district health administration of the Dangme West District to officially discuss the entire data collection process with them. A formal meeting was arranged within seven days after the first visit for the researchers to brief the health administration on the objectives of the study. The eleven participants for key informant interviews were selected with the help of the district Public Health Nurse. A copy of the guide was sent to participants ahead of interviews to enable interviewees to provide detailed information and to remove any element of surprise that the interview questions may have posed to participants. Each participant was given an informed written consent form to sign prior to the start of interview. Before interviews, participants were assured that information provided would not be related to the personal identities in any way. Initial interview questions centered on participants' background, qualifications, experience and current roles.
Interviewees were then asked about the nature of antenatal services, cultural factors affecting pregnancy outcomes and the main challenges affecting maternal health outcomes in the district. The English language, the official language of Ghana, was used for interviews with interviews ranging from forty-five minutes to one hour. With participants' consent, all interviews were audio recorded.

The FGDs followed a similar process to that of the key informant interviews. The head midwife in each of the selected health facilities assisted the investigators in selecting the respondents for the study. The midwives explained the purpose of the study to pregnant women at the clinic two weeks before the data collection. Women who showed interest in the study were contacted and directed to the venue for the FGDs by midwives. Each participant was given an informed written consent form to sign prior to the start of the discussions.

The FGD data collection started with the appointment of a moderator. A senior nurse was appointed to moderate the discussions. Although the authors wanted to moderate the discussions, two main reasons accounted for the selection of the senior nurse to preside over the FGDs. First, the women who volunteered to be part of the discussions only 
spoke Ga-Adangme, an ethnic language that the authors could not speak or understand. The second reason was the recommendation of Krueger and Casey [24] who advised that a focus group moderator should be someone with indepth knowledge about the phenomenon under discussion, hence experienced senior nurse (Principal Nursing Officer) was chosen for the discussions. Prior to the focus groups, the authors discussed the rationale of the study and the relevance of each question with the moderator. Although moderators asked questions, the researchers were present at both focus group discussions and made clarifications where necessary. Before the discussions, the moderators welcomed participants and introduced themselves and the topic to participants. Participants were urged to share their experiences about maternal health services in the district and were also encouraged that there were no right or wrong answers, rather differing opinions were welcomed. The moderator stated a few ground rules, asking patients to put their phones on silent mode and allowing one person to talk at a time. Participants' consent was sought before the group discussions were recorded. They were assured that their responses would be used only for research purposes and that no identifiable information would be given in the final research report in order to ensure anonymity. Both focus groups lasted for an average of ninety minutes. FGDs were conducted in Ga-Adangbe a local language in the district, and then translated into English by an expert translator. FGDs were respectively held in the conference room at the Integrated Unit of the Dodowa Government Hospital and a spacious meeting room of the Agomeda CHPS Zone. Item thirteen the Ghanaian version of refreshment was provided for the comfort of participants and a token was given to participants for transportation after the discussions.

\section{Data Analysis}

Data from in-depth interviews (IDIs) and FGDs were recorded and transcribed verbatim into word processor files. Data was read for familiar patterns and categories based on the objective of identifying socio-cultural factors that impinge on maternal health care delivery in the Dangme West District. Common patterns and categories were grouped into key themes that reflected the study objectives. In all, seven main themes were identified: the impact of patriarchal norms on maternal decisions; the influence of family tradition on maternal care, the impacts of the CHPS on maternal health services, and the relevance of cultural beliefs on food choices during pregnancy. The other issues broached included the effects of religious beliefs on maternal health outcomes, poverty and infrastructural considerations, and their influence on the delivery of maternal health services. Verbatim statements are quoted to reflect key themes identified in the analysis process.

\section{Strategy to Ensure Study Rigor}

Rigour for this study was ensured, using Tracy's Eight “BigTent" [25] criteria for excellent qualitative research. This was further supported by Whittemore, et al. [26] contemporary synthesis of validity criteria in qualitative research. The contemporary synthesis of validity criteria by Whittemore, et al. [26] and colleagues is made up of three levels: primary criteria, secondary criteria, and techniques. We employed two qualities from each of the two authorities to discuss the rigor strategy for this study. These include: credibility and sincerity of Tracy's 'Eight Big Tent'; and explicitness and authenticity in Whittemore, et al. contemporary synthesis of validity. Credibility in qualitative research is a process of ensuring honesty and plausibility of the research findings and this should reflect in the researchers' explanatory analyses to make it acceptable and persuasive. [25] The credibility of the findings should encompass all other qualities highlighted by Tracy. One way to ensure credibility in qualitative research is multivocality, which Tracy [25] explains as ensuring the presence of multiple and diverse voices in the qualitative report and analysis. Sincerity, according to Tracy [25], should mirror the authenticity of the research process with respect to the investigator's bias in achieving the aims of the study. Sincerity in this context requires the self-reflexivity of the investigator in every step of the study, beginning with the framing of the researcher's question to data collection, analysis, and interpretation [25]. Explicitness is another quality principle of validity check in qualitative research that we adopted in our study. Explicitness focuses on how methodological verdicts, interpretations, and researchers' biases are solved in a proposed study [26]. The final quality criterion for this study was authenticity. Authenticity often investigates whether the representations of the social groups' viewpoint exhibit awareness to the subtle differences in the voices of all participants [26]. The authenticity of the investigator allows for a reflection on the meanings and experiences of participants within a given situation which demands him/her to declare his/her positionality. In addition, the investigator's authenticity is often reflected in the detailed accounts of the phenomenon understudy through to the formation of major and sub-themes.

\section{Ethics}

Primary ethics approval for the study was obtained from the Institutional Review Board of the Dodowa Health Research Centre approval number DHRC-IRB CPN 02/02/13 revd.2013. Besides the approval, important ethical principles were strictly followed during data collection. In addition to receiving informed written consent, researchers ensured participants that their interviews were conducted in strict confidentiality. For instance, verbal and written consent were sought from participants before the data collection 
instruments were administered. This was done by asking participants to sign and return all consent forms preceding the interviews and FGDs. Participants were informed that their participation was voluntary and were free to withdraw from the study at any point in time.

\section{Results and Discussion}

According to the study findings, an important issue affecting maternal health in the district is poverty. Interview participants believe that endemic poverty in the district affects pregnant women in many ways. First, many women are not able to visit health facilities on time because of transportation cost and must wait until they are able to raise money. Second, women who come to health facilities are not able to afford prescribed medications and tests not covered by national health insurance, making their condition management very difficult. Respondents also stated that pregnant women in the district find it difficult to visit hospitals when referred for further treatment due to financial difficulties.

Interviews revealed that the Dangme West District is a strong patriarchal society. This permeates every facet of the Dangme society including maternal health decisions. What is surprising here is that an over-dependence on men means that pregnant women must wait for their husband's opinion on pregnancy issues even in times of emergency for decisionmaking and financial assistance. Focus groups revealed that this issue was also connected to funds. Most women in the district depend on their husbands for money and are not able to go to health facilities in the absence of their husbands or do not consider their conditions serious enough to warrant a hospital visit. Interviewed midwives believe this makes it difficult for pregnant women to seek maternal health care services and make the requisite number of ANC visits to health facilities. A senior midwife stated that;

"When they come and we ask them why didn't you come earlier or why didn't you come yesterday?...they will say my husband travelled, my husband was not around....We are well aware of the same excuse of my husband not being around when it happened... so we always remind women during ANC to plan for their child birth the moment they find out that they are pregnant"(Midwife).

Surprisingly, although women rely on their husbands for decision-making on key maternal decisions, men show less support or commitment on maternal issues. Interviews revealed that men hardly accompany their wives to ANC visits even when health personnel advise women to bring their husbands in for their next visit. During FGDs, probing revealed that men feel pregnancy is usually a woman's affair and are not sure of what they will be doing in hospitals when they should be at work. One respondent who was a community health nurse could not hide her frustration: "It is a pity that the men don't help their wives at all. In fact, husbands should be educated to be part of ANC in order to understand and assist their wives during pregnancy, especially when they are due for labour" (FGD 1 \&2 participants).

Findings suggest that the introduction of the CHPS program has affected maternal health care positively in the district. The CHPS concept was designed to offer primary care services in remote and hard-to-reach areas. Interviews show that although the program was meant to offer general health care to communities, there is more emphasis on maternal health care services as these facilities are usually patronized by women who need ANC. Health authorities interviewed stressed the above point and added that more CHPS compounds are planned for the coming years to create more access to women. The reason being that it is relatively cheaper and simple to build compared to building hospitals and health centers; a scenario which makes sense given the limited resources available to health authorities. FGDs revealed that the CHPS program has increased access to maternal health services as pregnant women do not need to travel to the district hospital at Dodowa for basic care. The only misgivings expressed here were that women wished these facilities offered more integrated maternal services as they struggle with referrals because of transportation costs and bad roads to the district hospital:

"The numerous CHPS compounds and zones built in the communities give us easy access to basic antenatal and postnatal care, but the lack of specialized care in such facilities is worrisome due to the difficulty involved in travelling to the district when referred" (FGD 1 participant).

Facility-based delivery by a skilled birth attendant is considered ideal for every pregnant woman. Consequently, a key issue that came up during interviews was the place of delivery. Respondents complained that the usual practice for women who stay in the remote parts of the district is to give birth with TBAs and in some cases, in prayer camps. This was even true with women who come to health facilities for ANC during pregnancy. Interviews with health care professionals revealed that such a preference for TBAs is in keeping with family tradition, as well as for proximity purposes. A key informant explained as follows;

"In most of the villages, pregnant women deliver using TBAs and in some instances at prayer camps simply because that is where their mothers went for delivery. You also know that usually their mothers move in and stay with them during the later stages of the pregnancy to take care of them and advise them, so they listen to suggestions from them. Besides, due to the small size of the communities, they know 
each other and if there are TBAs in the communities they are aware of them and will always go to them"(CHN).

Closely related to the above was the issue of birth position. Findings show that rather than lie on a bed during delivery, which allows midwives full access to examine and easily assist in the process of labour, some women prefer to squat. One participant in focus group 2 opined as follows;

"For me, I believe it is easy when squatting because when you are lying down, it's like you are relaxed on a bed. It is a serious matter, so you cannot be lying down. When you are squatting, all you need is for someone to hold the baby so that it does not fall to the ground" (FGD 2 participant).

Good nutrition in the form of a balanced diet during pregnancy is necessary for both the mother and the unborn baby. However, food-related taboos in the Dangme West District prevent pregnant women from eating a balanced diet due to their cultural beliefs. Health personnel described the impact of poor dietary habits among pregnant women in the district. A discussant, who was identified as a midwife, explained:

"Some pregnant women refuse to eat nutritious diet because they consider certain foods as taboos per their cultural beliefs. Foodstuffs such as eggs, certain types of fish, fatty meat, and some vegetables are abandoned by women for fear of fetal abnormality, abortion, and fatty baby" (Midwife).

FGDs with women revealed this to be true as some respondents admitted not eating snails and eggs during pregnancy. A few others, however, stated that they avoid snails and crabs because of their religious affiliations and cultural beliefs, as certain food types are regarded as unclean during pregnancy. A respondent in FGD 2 stated unequivocally that:

"Some pregnant women refuse to eat nutritious diet because they consider such food items [eggs, snails, fish, and fatty meat] as a taboo during pregnancy" (FGD 2 participant).

Key and common issues that run through responses of key informants and FGD participants have been summarized in Table 3.

\begin{tabular}{|l|}
\hline \multicolumn{1}{|c|}{ Key comments } \\
\hline 1. Patriarchal societies mean men make most decisions on maternal issues. \\
\hline 2. Family tradition influences where women are delivered. \\
\hline 3. CHPS has increased access to maternal health care services in the district. \\
\hline 4. Cultural beliefs influence food choices for pregnant women. \\
\hline 5. Religious beliefs influence who to consult during pregnancy. \\
\hline 6. Endemic poverty impacts negatively on maternal health outcomes in the district. \\
\hline 7. Road and health infrastructure need to be improved in the district. \\
\hline
\end{tabular}

Table 3: Key comments on maternal issues from interview respondents.

An interesting issue that was particularly stressed in both focus groups was the attitudes and behaviour of some midwives and nurses during delivery. Respondents mentioned that it is usual to expect shouting, lack of empathy, slapping of thighs, and utter disdain from nurses and midwives regarding the delivery process. Some women stated that sometimes it is disheartening for them to abused by small girls during hospital visits, especially during the delivery process. These negative behaviors of some midwives and nurses who attend to clients during ANC and labour, in effect, discourage some mothers from visiting the facility for maternal health care services. The actions of health providers in this regard take away women's autonomy and make them feel disrespected.

The religious affiliation of pregnant women and its impact on pregnancy outcomes in the district was discussed by both by participants in interviews and FGD respondents.
Participants argued that some pregnant women avoid the use of health facilities for delivery purposes because they pay more attention to their religious beliefs and doctrines. Focus groups revealed that women believe that pregnancy has a spiritual connotation that must be tackled if they are to deliver and be safe with their babies. There is the notion that witches, evil spirits, and rivals in the case of polygamous homes could work against the pregnant woman or her baby. Consequently, some pregnant women take advice concerning the care of their pregnancies and place of delivery from their pastors, prayer leaders or traditional priests depending on where their religious inclination is. Thus, in most instances, pregnant women visit pastors or traditional priests and herbalists to check the progress of their pregnancy, instead of using ANC services for professional care. Sometimes women are brought to the health facilities at a point when complications have arisen, and the risks of poor outcomes are very high. 
Knowledge of pregnancy and signs of labor by pregnant women is key in avoiding undue delays during labor. However, a significant number of pregnant women in the district lack basic knowledge of labor signs according to midwives and community nurses. Probing further revealed that this issue ties in with low literacy rates in the district. The few women who understand the signs of labour when they are happening are unable to act because of such factors as their husbands not being around, preference for traditional home birth, financial challenges, and distance to health facilities. Health personnel also indicated that although they do their best to educate women during ANC visits, the situation does not improve. They believe that they must scold pregnant women to ensure that they take issues more seriously. Pregnant women, however, believe that this could be done in a more respectful and empathetic way. A key informant opined that;

"Pregnant women's inability to identify labor signs is a huge challenge in the district. Some clients end up saying they did not know it was labor until it advanced.... meanwhile, we educate them on these things during ANC visits but because most of them do not come but go elsewhere, they do not know anything...They only bring them at the ninth hour"(Midwife)

Respondents spoke of the poor road network of the district. In the remote villages, pregnant women have to be transported on motorbikes or bicycles in order to have access to nearby CHPS compounds. The poor road infrastructure means that commercial vehicles do not ply such roads and even where they do, they charge high transport fares. Pregnant women fear for the safety of their pregnancies and therefore, avoid health facilities altogether unless it is an emergency. Respondents complained bitterly about how the poor road network in the district hinders maternal health care services. According to the findings, the deplorable nature of the roads and the long-distance travel makes it difficult for community health nurses to provide the needed services to clients, especially in the Osudoku area where the communities are far from each other. A key informant from the District Health Administration stated that;

"It's very difficult to move within communities as well as moving from one facility to the other for outreach programs. The roads are very bad, and staff sometimes have to use motorbikes [Okada] before reaching some facilities to serve clients. Also, the district is sparsely populated, and the poor road network makes accessibility a big problem" (Public Health Officer).

Regardless of the potential benefits of the uptake of maternal health services to pregnant mothers and their unborn babies, many expectant mothers refuse to use available services in rural Ghana. The study provides evidence on the impact of sociocultural factors on pregnancy outcomes in the district which are mostly consistent with available literature in other parts of Ghana. $[9,12,27]$ Our results reveal that women in the Dangme West District go through several challenges to access maternal health care services. These include poor road network, long distance travels between home and health facilities, and non-availability of specialized services. The aforesaid challenges compel some women to abandon facility delivery to use the services of TBAs which sometimes affect the outcomes of their pregnancies. This assertion is consistent with UNFPA [28] and Adu, et al. [29] that long distances to healthcare facilities are an obstacle to accessing healthcare services promptly. Even though the WHO recommends that all pregnant women within the first trimester should receive ANC regardless of their health status and be examined by skilled attendants to rule out any hidden conditions associated with the pregnancy [5], this is still far from being achieved in many parts of the district.

It must be noted that these challenges have been identified even in the face of increased access through the CHPS concept. However, the absence of integrated health services at the various CHPS compounds due to inadequate human resources for basic care in such facilities means pregnant women still lack access to certain maternal care services. By this development, the purposes of the CHPS compounds as the first point of call in the community anytime one is sick, particularly when pregnant women are in labor is defeated. This suggests that the provision of health professionals is as important as the construction of CHPS compounds in rural communities for the delivery of maternal health care services in the Dangme West District. The availability of human resources for health care and equitable distribution is essential in the provision of maternal health care services in order to reduce maternal deaths and disabilities. [8] While there is a lack of specialized care, women are in fact, opting for what they know to be a culturally accepted approach by consulting with their spiritual fathers in prayer camps. This phenomenon is, however, not unique to the Dangme West District as this has been noted in other parts of Africa such as Kenya, where the absence of care and the poor treatments received by poor women from skilled birth attendants in health facilities push women to use less efficient services at their disposal $[8,30]$.

In several traditional African societies, male dominance is an issue and the fight for gender equality is only gathering momentum [31,32]. This has been a cultural issue as campaigns for girl child education intensified in the past few decades in Ghana, albeit this issue still persists in rural localities. The result of this has been a society in which most decisions are made solely by men, including maternal issues where women's opinion is paramount. The patriarchal system also affects the economic standing of women as respondents in this study attributed the endemic poverty 
amongst women in the district to the high patriarchal society and the over-dependence on men for financial support during pregnancy, labor, and after childbirth. Pregnant women have had to abide by decisions made by their husbands regarding the care of their pregnancy and have been coerced to use the services of TBAs due to lack of money for transportation and purchase of drugs; a familiar phenomenon in many lowincome countries [31]. The traditional gender roles of men as breadwinners and decision makers in the household is a well-established barrier to facility delivery in rural areas [31].

Closely related to the above is the role of men in maternal issues. It is a bit paradoxical to note that despite making key decisions on maternal issues, men hardly take an active part in ensuring the safety of their wives and unborn babies. Respondents in this study noted that the culture of husbands not taking an active part in maternal health care services ANC, labour, and post-natal care in Ghana should be looked at by policymakers. Some respondents reiterated this and further indicated that lessons received by men during ANC will inform them on the importance of facility-based delivery of their pregnant wives. This finding aligns with previous studies in Africa that emphasize maternal health as important to the whole society $[1,2]$. The willingness of men to fully support their wives before, during, and after labour as seen in the developed world can help avert the problem stated by WHO [5] and [27]; that women do not, and probably often cannot embark on care-seeking paths even when they know that they have a life-threatening condition due to cultural constraints. In Ghana, this was put in a better perspective by Abass, et al. [33] that in some parts, prolonged labour is seen as a sign of infidelity. In these cases, families with men making key decisions refuse to treat such cases as an emergency, but rather rely on their elders to appease the gods of the land to help with the delivery process [33]. Undue delays are thus caused in the process which can result in the death of a woman or leave her with a disability. Husbands who are knowledgeable in maternal issues, however, will resist such negative cultural practices and avoid the three delays as discussed by Thaddeus, et al. [20], making decisions that will improve pregnancy outcomes.

Midwives interviewed were concerned about the lack of knowledge on labor signs by some pregnant women in the district. This could cause an undue delay among mothers in visiting health facilities on time to seek professional care. Many factors could account for women's inability to observe labor signs, including illiteracy, lack of maternal education due to women's refusal to attend ANC, others paying no attention to lessons during ANC, and lack of autonomy. These problems according to Thaddeus, et al. [20], form the basis of the first and second delays: delay in decision to seek care and delay in reaching an adequate health care facility which could result in maternal death.

Cultural and religious dogmas were acknowledged by many respondents as a key issue affecting maternal health outcomes in the district. This issue becomes even more important where community members become entrenched in their traditional beliefs and tend to be overly protective of such beliefs as prevails in the Dangme West District. For instance, food-related taboos in the district prevent pregnant women from eating foodstuffs nutritious in iron which is vital for the health of pregnant women and their unborn babies. It must be noted that this occurs in other parts of the world especially in India and most South Asian countries as women who are deprived of such healthy food and are poor become malnourished which subsequently result in anemia in pregnancy [34]. This contributes to the likelihood of poor health outcomes for both mother and baby as it affects the capacity to have a healthy labour and delivery, as well as the size of the newborn and lactation.

As noted already, others are compelled to follow their family tradition of not using ANC and facility delivery during pregnancy and childbirth. TBAs, therefore, become the main point of contact for maternal health care. This is consistent with Malin, et al. [35] who pointed out that the health of the pregnant woman is managed traditionally based on several pre-determined and experienced beliefs within specific cultural settings. The continuous reliance on TBAs rather than skilled birth attendants could be a recipe for infection, unmanaged post-partum haemorrhage, inversion of the uterus and laceration of the cervix. This is because TBAs have little or no knowledge on aseptic techniques and may end up introducing infections into the womb of mothers during labor; a situation which could result in the death of women within their puerperium period and beyond, especially in areas where basic obstetric care is lacking to treat such complications. Health authorities need to work more closely with local community leaders, TBAs and women's groups to increase the uptake of facility delivery while also educating health care providers on culturally appropriate and womancentered care [36]. This will help to reduce or eliminate the inherent cultural practices within the various communities in the district.

\section{Conclusion}

This study has shown that there are several problems in maternal health care delivery in the Dangme West District of Ghana although some improvements have been made with the construction of a few CHPS facilities. The study has produced findings that are consistent with other studies in the northern part of Ghana [33]. In general, it is obvious that issues such as illiteracy, poverty, lack of skilled attendants, and poor maternal infrastructure characterise low uptake of 
maternal health care services in both the North and South of Ghana and can be viewed as societal issues. The lack of basic knowledge on pregnancy and childbirth among women coupled with poverty, lack of skilled professionals and modern health facilities have contributed largely to the low facility deliveries in rural Ghana. Cultural differences between the North and South, however, suggest that some differences can still be identified. Though a significant proportion of women still give birth in various places outside of health facilities in the Northern and Southern Ghana, studies have shown that in Northern Ghana, the strength of a woman, usually compared to rivals in polygamous marriage, regarding her ability to give birth by herself as well as her fidelity to her husband are the main reasons behind home delivery. In the Dangme West, however, this is simply due to the preservation of family traditions of mothers of pregnant women not giving birth in health facilities. Besides, this study shows that some women in the Dangme West attach high importance to posture during labour and prefer squatting over lying on a hospital bed. This preference influences their decision to give birth with TBAs or at home even after attending ANC. It is, however, clear that whether in Northern or Southern Ghana, there is need to improve infrastructure and logistics and increase maternal health educational campaigns in the various rural communities to raise awareness among women on the importance of ANC and facility-based delivery. Health promotional activities should be aimed towards ensuring that women are made to feel safe, respected and cared for if they decide to come to health care facilities.

\section{References}

1. Annan K (2010) Maternal Health: Investing in the lifeline of healthy societies and economies. Policy Brief: 1-36.

2. Ransom EI, Yinger N V, Sass J (2002) Making Motherhood Safer - Overcoming Obstacles on the Pathway to Care: $1-34$.

3. Fathalla MF (2006) Human rights aspects of safe motherhood. Best Pract Res Clin Obstet Gynaecol 20(3): 409-419.

4. Hogan MC, Foreman KJ, Naghavi M, Ahn SY, Wang M, et al. (2010) Maternal mortality for 181 countries, 1980-2008: a systematic analysis of progress towards Millennium Development Goal 5. Lancet 375(9726): 1609-1623.

5. Walt G (2004) WHO's World Health Report 2003. BMJ 328(7430): 6 .

6. Campbell OM, Graham WJ (2006) Strategies for reducing maternal mortality: getting on with what works. Lancet 368(9543): 1284-1299.

7. World Health Organization (2011) Trends in maternal mortality: 1990-2015: estimates from WHO, UNICEF, UNFPA WBG and the UNP. Chronic monitoring of bladde. Can J Urol 18(1): 5504-5516.

8. Gyimah SO, Takyi BK, Addai I (2006) Challenges to the reproductive-health needs of African women: On religion and maternal health utilization in Ghana. Soc Sci Med 62(12): 2930-2944.

9. World Bank T (2011) Trends in maternal mortality, 1990-2008. Popul Dev Rev 37(1): 211-214.

10. Srivastava A, Avan BI, Rajbangshi P, Bhattacharyya S (2015) Determinants of women's satisfaction with maternal health care: A review of literature from developing countries. BMC Pregnancy Childbirth 15(1): $1-12$.

11. HERA (2013) Evaluation of the Free Maternal Health Care Initiative in Ghana, pp: 1-56.

12. Yakong VN, Rush KL, Bassett-Smith J, Bottorff JL, Robinson C (2010) Women's experiences of seeking reproductive health care in rural Ghana: Challenges for maternal health service utilization. J Adv Nurs 66(11): 2431-2441.

13. Moyer CA, Adongo PB, Aborigo RA, Hodgson A, Engmann CM, et al. (2014) 'It's up to the woman's people': How social factors influence facility-based delivery in Rural Northern Ghana. Matern Child Health J 18(1): 109-119.

14. Hill E, Hess R, Aborigo R, Adongo $\mathrm{P}$, Hodgson A, Engmann C, et al. (2014) 'I don't know anything about their culture': the disconnect between allopathic and traditional maternity care providers in rural northern Ghana. Afr J Reprod Health 18(2): 36-45.

15. Fulton JP, Buechner JS, Scott HD, DeBuono BA, Feldman JP, et al. (1991) A study guided by the Health Belief Model of the predictors of breast cancer screening of women ages 40 and older. Public Health Rep 106(4): 410-420.

16. Glanz K, Rimer BK LF (1992) Health Behavior and Health Education: Theory, Research, and Practice. Ann Intern Med 116(4): 350.

17. Janz NK, Becker MH (1984) The Health Belief Model: A Decade Later. Heal Educ Behav 11(1): 1-47.

18. Nutbeam D, Harris E (2004) Theory in a nutshell: A practical guide to health promotion theory $2^{\text {nd }}(E d n)$.28 : 1-2.

19. Jegede A (2002) The Yoruba Cultural Construction of Health and Illness. Nord J African Stud 11(3): 322-335. 
20. Thaddeus S, Maine D (1994) Too far to walk: Maternal mortality in context. Soc Sci Med 38(8): 1091-1110.

21. (2012) 2010 Population and Housing Census Final Results Ghana Statistical Service, Summary Report of Final Results, pp: 1-103.

22. Yin R (2016) Case Study Research Design and Methods $5^{\text {th }}$ (Edn.), Thousand Oaks, CA. Can J Progr Eval 1(2014): 108-110.

23. Black K (2010) Business Statistics: Contemporary Decision Making. $6^{\text {th }}$ (Edn.) JW\& S 53: 1689-1699.

24. Krueger RA, Casey MA (2015) Focus Group Interviewing. Handb Pract Progr Eval $4^{\text {th }}$ (Edn.), pp: 506-534.

25. Tracy SJ (2010) Qualitative quality: Eight Big-Tent criteria for excellent qualitative research. Qual Inq 16(10): 837-851.

26. Whittemore R, Chase SK, Mandle CL (2001) Validity in Qualitative Research. Pearls, Pith, and Provocation 11(4): 522-537.

27. Mantey J (2013) Maternity Mortality Remains High in Ghana. Voa, pp: 11-13.

28. UNFPA (2012) Maternal Health Thematic Fund Annual Report 2011, pp: 84.

29. Adu J, Tenkorang E, Banchani E, Allison J, Mulay S (2018) The effects of individual and community-level factors on maternal health outcomes in Ghana. PLoS One 13(11):
$1-16$.

30. Izugbara CO, Ngilangwa DP (2010) Women, poverty and adverse maternal outcomes in Nairobi, Kenya. BMC Womens Health 10: 33.

31. Brubaker K, Nelson BD, McPherson H, Ahn R, Oguttu M, Burke TF (2016) Qualitative study of the role of men in maternal health in resource-limited communities in western Kenya. Int J Gynecol Obstet 135(3): 245-249.

32. Kabeer N (2005) Gender Equality and Women's empowerment: A critical analysis of the third millennium development goal 1. Gender \& Development 13(1): 1324.

33. Abass K, Sakoalia P, Mensah C (2009) Socio-Cultural Practices and Male Involvement in Reducing Maternal Mortality in Rural Ghana. The Case of Savelugu/Nanton District of the Northern Region of Ghana. Int J Asian Soc Sci 2(11): 2009-2026.

34. Kalaivani K (2009) Prevalence and consequences of anaemia in pregnancy. Indian Journal of Medical Research 130: 627-633.

35. Malin M, Gissler M (2009) Maternal care and birth outcomes among ethnic minority women in Finland. BMC Public Health 9: 1-14.

36. Adu J (2013) Localizing the Millenium Development Goals (MDGs) in Ghana: An Assessment of Goal Five in the Dangme West District, pp: 2-128. 